\title{
Atypische Anorexie
}

\section{0 kg Gewichtsverlust - das kann auch ohne Untergewicht schädlich sein}

\section{Wenn Mädchen in der Pubertät plötz- lich stark abnehmen, hat das ähnliche körperliche und psychische Konsequen- zen wie bei einer Anorexie: Die Regel- blutung bleibt oft aus, der Puls ist zu niedrig und Depressionen sind häufig.}

_ Anorexiesymptome können auch vorliegen, wenn normal- oder übergewichtige Personen plötzlich drastisch abnehmen. Sind bis auf das Untergewicht sämtliche Kriterien für eine Anorexie erfüllt - z. B. gestörtes Körperschema und Fixierung auf Kalorienvermeidung -, spricht man von einer atypischen Anorexie.

256 Jugendliche mit Verdacht auf eine Essstörung wurden in einer australischen Studie körperlich und psychisch untersucht. Dabei stellten die Ärzte bei
118 Patienten (46\%) eine Anorexie, bei 42 (16\%) eine atypische Anorexie fest.

Bei der psychologischen und körperlichen Untersuchung gab es kaum Unterschiede zwischen beiden Gruppen: Der Ruhepuls war bei atypischer Anorexie ähnlich niedrig wie bei der klassischen Form, auch der Anteil der Patienten mit Hypothermie war ähnlich. 32 vs. $61 \%$ der Jugendlichen hatten eine Amenorrhö. Jugendliche mit der atypischen Form zeigten noch stärkere Symptome einer Essstörung. Sie hatten ein negativeres Körperbild als die deutlich dünneren Jugendlichen mit klassischer Anorexie. Psychiatrische Komorbiditäten (38 vs. $45 \%$ ), Suizid- und Selbstschädigungsgedanken ( 43 vs. $39 \%$ ) waren bei beiden Verlaufsformen ähnlich häufig. Eine De-

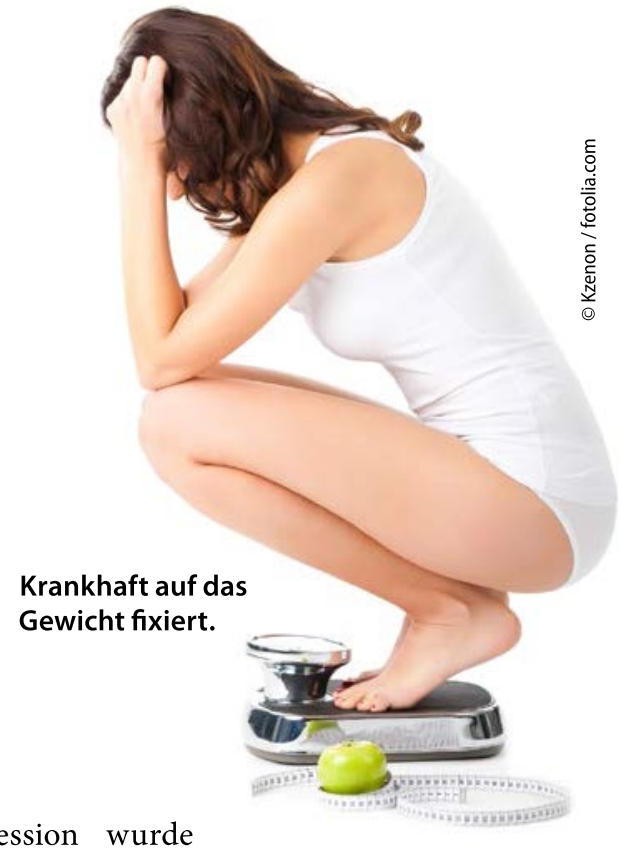

jeweils bei rund einem Drittel diagnostiziert, eine Angststörung bei 17 und $24 \%$, eine Zwangsstörung bei 5 und $6 \%$.

- mut

- Sawyer S M et al. Pediatrics 2016, online 29. März 2016; DOI: 10.1542/peds.2015-4080

\section{Hier steht eine Anzeige.}

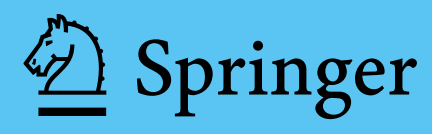

